\title{
Effect of alkali treated jute fibres on composite properties
}

\author{
DIPA RAY, B K SARKAR*, A K RANA ${ }^{\dagger}$ and N R BOSE \\ Department of Materials Science, Indian Association for the Cultivation of Science, Kolkata 700 032, India \\ †ndian Jute Industries Research Association, Kolkata 700 088, India \\ ${ }^{\ddagger}$ Central Glass and Ceramic Research Institute, Kolkata 700 032, India
}

\begin{abstract}
Jute fibres were subjected to a 5\% alkali (NaOH) solution treatment for $0,2,4,6$ and $8 \mathrm{~h}$ at $30^{\circ} \mathrm{C}$. An improvement in the crystallinity in the jute fibres increased its modulus by $12 \%, 68 \%$ and $79 \%$ after 4,6 and $8 \mathrm{~h}$ of treatment respectively. The tenacity of the fibres improved by $46 \%$ after 6 and $8 \mathrm{~h}$ treatment and the $\%$ breaking strain was reduced by $23 \%$ after $8 \mathrm{~h}$ treatment. For the 35\% composites with $4 \mathrm{~h}$ treated fibres, the flexural strength improved from 199.1 MPa to 238.9 MPa by $20 \%$, modulus improved from 11.89 GPa to 14.69 GPa by $23 \%$ and laminar shear strength increased from $0.238 \mathrm{MPa}$ to $0.2834 \mathrm{MPa}$ by $19 \%$. On plotting the different values of slopes obtained from the rates of improvement of the flexural strength and modulus, against the $\mathrm{NaOH}$ treatment time, two different failure modes were apparent before and after $4 \mathrm{~h}$ of treatment. In the first region between 0 and $4 \mathrm{~h}$, fibre pull out was predominant whereas in the second region between 6 and $8 \mathrm{~h}$, transverse fracture occurred with a minimum fibre pull out. This observation was well supported by the SEM investigations of the fracture surfaces.
\end{abstract}

Keywords. Vinylester resin; jute fibre composite; alkali; mechanical properties; fracture; fibre pull out.

\section{Introduction}

In recent years, the natural fibre reinforced composites have attracted substantial importance as a potential structural material. The attractive features of the natural fibres like jute (Roe and Ansell 1985; Shah and Lakkad 1981), sisal (Bisanda and Ansell 1991), coir (Prasad et al 1983; Rout et al 1999) and banana (Pothan et al 1997) have been their low cost, light weight, high specific modulus, renewability and biodegradability. Naturally, composites reinforced with such natural fibres have thus been a subject of intense study for low strength, low cost application in contrast to the synthetic fibre reinforced composites. Since the interfacial bond between the reinforcing fibres and the resin matrix is an important element to realize the mechanical properties of the composites, studies have been focussed on the treatment of fibres to improve the bonding with resin matrix by several authors (Samal et al 1995; Gassan and Bledzki 1999a, b). Amongst the several natural fibres, jute constitutes a major area of investigation.

For the composite applications having good bonding between the fibre and the resin matrix, jute have been treated with alkali, a process known as mercerization, being commercialized for cotton fibres for superior reactivity with dyes (Ott et al 1954). Several authors have employed the technique on jute and the changes occurring in the fibre properties were investigated (Sarkar 1935; Mukherjee et al 1993). Sarkar (1935) and Samal et al

\footnotetext{
*Author for correspondence
}

(1995) have treated jute fibres with $\mathrm{NaOH}$ solution of concentration $1 \%, 8 \%$ for $48 \mathrm{~h}$ and $2 \%$ for $1 \mathrm{~h}$ and showed improvements in fibre properties by $130 \%$ and $13 \%$ respectively. Similar treatments were attempted by Gassan and Bledzki (1999a, b) on isometric jute yarns. They reported an improvement of $120 \%$ and $150 \%$ in the tensile strength and modulus of jute yarns respectively treated with $25 \% \mathrm{NaOH}$ solution for $20 \mathrm{~min}$ and $60 \%$ improvement in the jute/epoxy composite properties reinforced with these treated yarns. The improvements have been attributed to the greater reactivity of the treated fibres with the resin administering superior bonding.

In this study, the effects of $5 \% \mathrm{NaOH}$ treatment for short duration of up to $8 \mathrm{~h}$ on jute as reinforcing fibre material to vinylester resin have been investigated. Mechanical properties of the composites with varying weight $\%$ of fibres were determined. The change in properties were analysed with the help of microstructural analysis of the fractured surfaces.

\section{Experimental}

\subsection{Materials}

Jute fibres (white jute, Corchorus capsularis) were collected from Indian Jute Industries Research Association (IJIRA), Kolkata. Vinylester resin of grade HPR 8711, a Bakelite Hylam product was used. Methyl ethyl ketone peroxide (MEKP), Co napthenate and N,N-dimethylaniline were used as catalyst, accelerator and promoter respectively. 


\subsection{Alkali treatment}

The jute fibres were cut to $50 \mathrm{~cm}$ of length and were soaked in a $5 \% \mathrm{NaOH}$ solution at $30^{\circ} \mathrm{C}$ maintaining a liquor ratio of $15: 1$. The fibres were kept immersed in the alkali solution for 2, 4, 6 and $8 \mathrm{~h}$. The fibres were then washed several times with fresh water to remove any $\mathrm{NaOH}$ sticking to the fibre surface, neutralized with dilute acetic acid and finally washed again with distilled water. Final $\mathrm{pH}$ maintained was 7 . The fibres were then dried at room temperature for $48 \mathrm{~h}$ followed by oven drying at $100^{\circ} \mathrm{C}$ for $6 \mathrm{~h}$.

\subsection{Dispersability test}

A simple test was performed to observe the dispersability of the untreated and the alkali treated fibres in vinylester resin. Alkali treated jute fibres were found to have dispersed more uniformly in the resin than the untreated jute fibres.

\subsection{Composite processing}

The jute/vinylester composites containing the raw and alkali treated jute fibres were fabricated in the form of cylindrical rods of diameter $6 \mathrm{~mm}$. Hollow cylindrical glass tubes of internal diameter of $6 \mathrm{~mm}$ were taken to act as a mould. The resin was mixed with accelerator, promoter and catalyst (1\% each). The jute fibres were dried prior to use, soaked in the mixed resin and the wetted fibres were pultruded through the glass tube by hand.

The pultruded samples within the glass tube were cured at room temperature for $24 \mathrm{~h}$ followed by a post curing in an oven at $80^{\circ} \mathrm{C}$ for $4 \mathrm{~h}$. The glass tubes were broken clean to release the composite rod. The composites with five different wt $\%(8,15,23,30$ and 35$)$ of untreated and treated jute fibres were prepared for further investigation. In this case, both the wt $\%$ and vol\% are similar as the density of the resin and the fibre are both equal to $1 \cdot 3 \mathrm{~g} / \mathrm{cm}^{3}$.

\subsection{Test methods}

The fibres after different soaking times in 5\% alkali solution were tested for their weight change. The loss in weight was calculated by weighing a fixed amount of dry and cleaned fibre $\left(W_{1}\right)$. The amount of fibre was weighed again after soaking in alkali solution $\left(W_{2}\right)$. The $\%$ weight loss was calculated as

$$
\% \text { Weight loss }=\left(W_{1}-W_{2}\right) / W_{1} \times 100 .
$$

It was observed that the fibres were somewhat leached and were finer. Fibre fineness was determined in terms of linear density by gravimetric method. The linear density was obtained from the weight of 100 single fibres of $60 \mathrm{~mm}$ length each.

Chemical analysis of untreated and treated fibres were made to estimate the cause for the loss in weight. The major constituents ( $\alpha$-cellulose, hemicellulose and lignin) of the untreated and the alkali treated jute fibre samples were determined following the standard procedures (Chattopadhyay and Sarkar 1946).

Tensile tests of single jute fibres were carried out using an Instron 1195. A gauge length of $20 \mathrm{~mm}$ was employed with a cross head speed of $10 \mathrm{~mm} / \mathrm{min}$ in accordance with ASTM D 3822-91. Fifty single fibres were tested after each treatment and the mean value was reported.

Flexural Test: Three-point bend tests were performed in an Instron 4303 machine in accordance with ASTM D790M-81 to measure the flexural strength of the composites. Test specimens were $120 \mathrm{~mm}$ long cylindrical rods having a diameter of $6 \mathrm{~mm}$. A span of $100 \mathrm{~mm}$ was employed maintaining a cross head speed of $2 \mathrm{~mm} / \mathrm{min}$.

The flexural strength and modulus were measured using the following equations

$$
\begin{aligned}
& \text { Flexural strength }=8 \cdot F \cdot L / \pi \cdot d^{3}, \\
& \text { Flexural modulus }=4 \cdot m \cdot L^{3} / 3 \cdot \pi \cdot d^{4},
\end{aligned}
$$

where $F$ is the load, $L$ the span, $d$ the dia. of specimen and $m$ the slope of the initial straight line portion of the load-displacement curve.

The breaking energy was calculated from the area under the load/displacement curve to the break point and the toughness was obtained by dividing the energy to break by the volume of the test specimen.

The flexural interlaminar shear strength (LSS) of the composites which is the maximum shear stress that a material can withstand before it ruptures, was calculated in the stress units based on the area of the sheared edge.

\section{Results and discussion}

Loss in weight was observed after the alkali treatment of the fibres, shown in figure 1 , due to heavy dissolution of the hemicellulose content. The loss occurred primarily within $2 \mathrm{~h}$ of treatment. This had resulted in the drop of linear density of the fibres when treated between 2 and $6 \mathrm{~h}$ due to the creation of voids in the fibre structure, the strands became well separated and dispersed. The crystallinity of the fibres was observed to have increased only after $6 \mathrm{~h}$ treatment. By $8 \mathrm{~h}$ treatment, the $I_{002}$ peak height improved by $23.4 \%$ from the untreated fibre. The improvements in the properties of the untreated jute fibres and on alkali treatment is depicted in figure 2 . The modulus of the jute fibres increased by $12 \%$ at $4 \mathrm{~h}$ of treatment, after which the increase was by $68 \%$ and $79 \%$ when treated for 6 and $8 \mathrm{~h}$ respectively. The tenacity at break point increased by nearly $46 \%$ after 6 and $8 \mathrm{~h}$ treatment, $\%$ breaking strain was reduced by $23 \%$ after 
$8 \mathrm{~h}$ of treatment (figure 2). It was imperative that the fibres became stiff and brittle on account of its high strength and low extensibility. Similar increase in strength of jute fibres on alkali treatment was reported by Sarkar (1935).

\subsection{Mechanical properties of untreated jute fibre reinforced vinylester composites}

The properties of jute/vinylester composites are given in table 1. For each data point, minimum five samples were tested and the value given is the mean of those results. The load/displacement curves for $23 \mathrm{wt} \%$ and $35 \mathrm{wt} \%$ composites with both untreated and $4 \mathrm{~h}$ alkali treated fibres are shown in figure 3 . Heavy fibre pull out and breakage was observed for $23 \mathrm{wt} \%$ and $35 \mathrm{wt} \%$ fibre composites reinforced with untreated fibres. Shear fracture was predominant for alkali treated fibre composites,

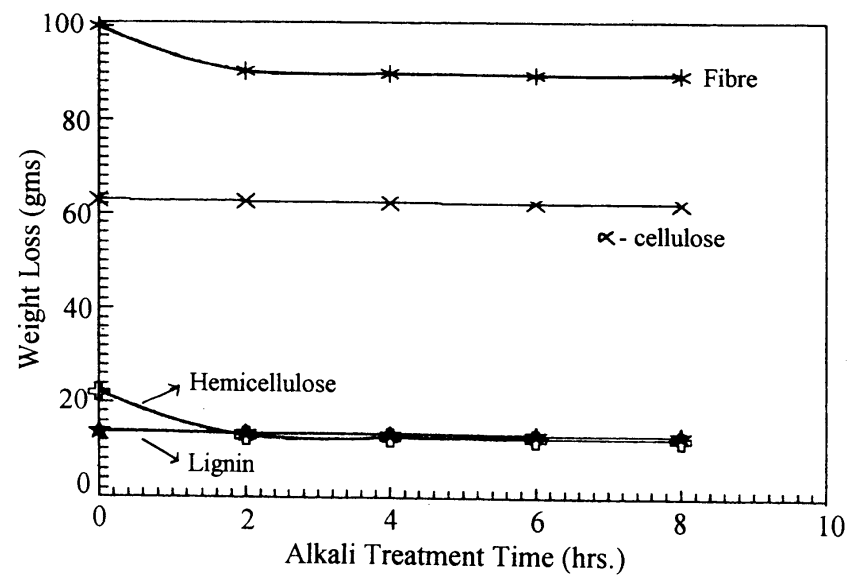

Figure 1. Loss of weight of the constituents of jute fibres after alkali treatment.

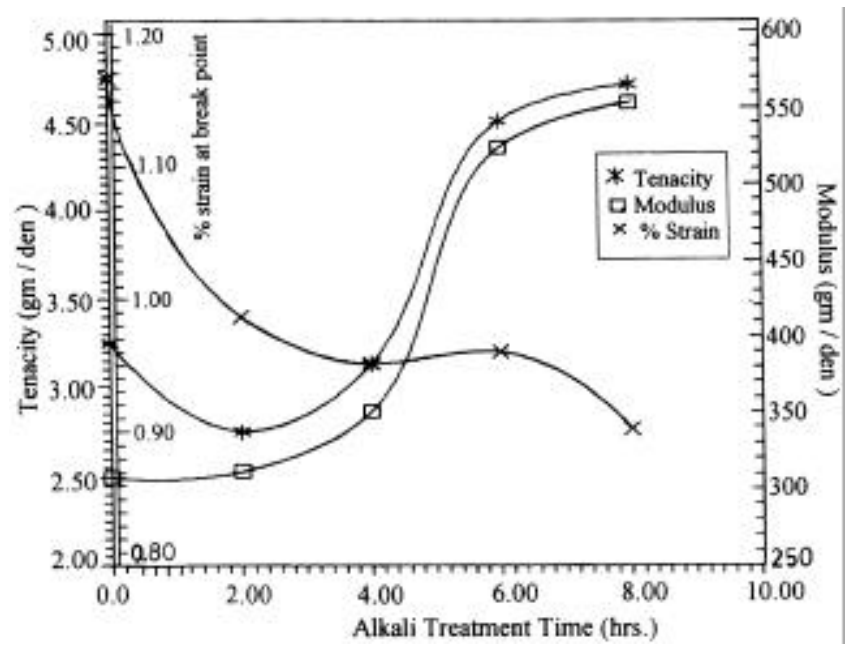

Figure 2. Tenacity, modulus and $\%$ breaking strain of jute fibres after alkali treatment with varying times. imperative of a better bonding at the interface between the fibre and the matrix.

In keeping with the general rule of mixtures, the improvements apparently have occurred linearly in modulus from 2.915 to $11.89 \mathrm{GPa}$, flexural strength from 120.70 to $199.1 \mathrm{MPa}$, for 8 to $35 \mathrm{wt} \%$ of fibres in the resin matrix. The initial lowering of the flexural strength with $8 \mathrm{wt} \%$ of fibre reinforcement than the properties obtained for the resin alone was in accordance with the rule of mixtures, i.e. when the volume fraction of reinforcing fibres is lower than the critical quantity, the fibres acted as flaws in the matrix (Milweski and Katz 1987). Such a drop in properties was observed by others also.

\subsection{Mechanical properties of alkali treated jute fibre reinforced vinylester composites}

The mechanical properties of composites prepared with varying proportions of fibres (0 to $35 \mathrm{wt} \%)$ treated with alkali (5\% $\mathrm{NaOH}$ solution) are included in table 1 . The composites prepared with fibres treated for $4 \mathrm{~h}$ showed maximum improvements at all wt $\%$ fibre loadings. The improvement became more predominant with increasing fibre loading. The flexural strength properties of the com-

Table 1. Mechanical properties of untreated and alkali treated jute/vinylester composites.

\begin{tabular}{|c|c|c|c|c|}
\hline $\begin{array}{l}\text { Jute } \\
\text { (wt } \%)\end{array}$ & $\begin{array}{l}\text { Type of } \\
\text { fibre }\end{array}$ & $\begin{array}{l}\text { Modulus } \\
(\mathrm{GPa})\end{array}$ & $\begin{array}{l}\text { Flexural strength } \\
(\mathrm{MPa})\end{array}$ & $\begin{array}{l}\text { Breaking energy } \\
(\mathrm{J})\end{array}$ \\
\hline 0 & - & $2 \cdot 915$ & $120 \cdot 70$ & $0 \cdot 8227$ \\
\hline \multirow[t]{5}{*}{8} & untreated & $4 \cdot 220$ & $106 \cdot 30$ & $0 \cdot 2948$ \\
\hline & treated $2 \mathrm{~h}$ & $3 \cdot 446$ & $96 \cdot 27$ & $0 \cdot 2497$ \\
\hline & treated $4 \mathrm{~h}$ & $4 \cdot 205$ & $121 \cdot 20$ & $0 \cdot 3634$ \\
\hline & treated $6 \mathrm{~h}$ & $3 \cdot 967$ & $101 \cdot 80$ & $0 \cdot 2270$ \\
\hline & treated $8 \mathrm{~h}$ & $3 \cdot 130$ & 93.97 & $0 \cdot 2488$ \\
\hline \multirow[t]{5}{*}{15} & untreated & $5 \cdot 544$ & 128.60 & 0.3399 \\
\hline & treated $2 \mathrm{~h}$ & $6 \cdot 024$ & $134 \cdot 70$ & 0.3530 \\
\hline & treated $4 \mathrm{~h}$ & 6.539 & $146 \cdot 50$ & 0.4016 \\
\hline & treated $6 \mathrm{~h}$ & $5 \cdot 546$ & $121 \cdot 50$ & $0 \cdot 2569$ \\
\hline & treated $8 \mathrm{~h}$ & $5 \cdot 337$ & $127 \cdot 60$ & $0 \cdot 3351$ \\
\hline \multirow[t]{5}{*}{23} & untreated & $7 \cdot 355$ & $145 \cdot 70$ & 0.3531 \\
\hline & treated $2 \mathrm{~h}$ & $8 \cdot 065$ & $157 \cdot 70$ & 0.4048 \\
\hline & treated $4 \mathrm{~h}$ & $9 \cdot 384$ & $172 \cdot 70$ & 0.4198 \\
\hline & treated $6 \mathrm{~h}$ & $8 \cdot 542$ & $155 \cdot 40$ & 0.3553 \\
\hline & treated $8 \mathrm{~h}$ & $7 \cdot 132$ & $145 \cdot 80$ & $0 \cdot 3762$ \\
\hline \multirow[t]{5}{*}{30} & untreated & $10 \cdot 030$ & $180 \cdot 60$ & 0.4799 \\
\hline & treated $2 \mathrm{~h}$ & $10 \cdot 990$ & $189 \cdot 40$ & 0.4816 \\
\hline & treated $4 \mathrm{~h}$ & $12 \cdot 850$ & $218 \cdot 50$ & 0.5061 \\
\hline & treated $6 \mathrm{~h}$ & $12 \cdot 490$ & 195.90 & 0.4319 \\
\hline & treated $8 \mathrm{~h}$ & $11 \cdot 170$ & $197 \cdot 50$ & 0.5042 \\
\hline \multirow[t]{5}{*}{35} & untreated & $11 \cdot 890$ & $199 \cdot 10$ & 0.5543 \\
\hline & treated $2 \mathrm{~h}$ & $12 \cdot 700$ & $205 \cdot 20$ & 0.4570 \\
\hline & treated $4 \mathrm{~h}$ & 14.690 & 238.90 & 0.5695 \\
\hline & treated $6 \mathrm{~h}$ & 14.890 & $232 \cdot 00$ & 0.5678 \\
\hline & treated $8 \mathrm{~h}$ & $12 \cdot 320$ & $204 \cdot 20$ & 0.5099 \\
\hline
\end{tabular}


posites at $35 \mathrm{wt} \%$ fibre loading after $4 \mathrm{~h}$ alkali treatment was $238.9 \mathrm{MPa}$ in contrast to $199.1 \mathrm{MPa}$ for the composites with untreated fibres. An improvement of $20 \%$ was measured. The improvements however, were $3 \%$ and $2.5 \%$ only for composites prepared with 2 and $8 \mathrm{~h}$ treated fibres respectively. The trend was similar for the lower loadings with the treated fibres. The improvement had occurred after $23 \mathrm{wt} \%$ fibre loading. Similar observations for the alkali treated coir reinforced polyester composites at $19 \mathrm{wt} \%$ loading was reported by Rout et al (1999). The trend was similar for the flexural modulus also. The maximum improvements were with $4 \mathrm{~h}$ treated fibre composites at $35 \mathrm{wt} \%$ reinforcements. For $4 \mathrm{~h}$ treated fibre composites at $35 \mathrm{wt} \%$ loading showed strengths in the range of $28.34 \times 10^{-2} \mathrm{MPa}$. For the composites prepared with $8 \mathrm{wt} \%, 15 \mathrm{wt} \%$ and $23 \mathrm{wt} \% 4 \mathrm{~h}$ treated fibres, the breaking energy values increased by $23 \%, 19 \%$ and $18 \%$ respectively, whereas for the composites with $30 \mathrm{wt} \%$ and $35 \mathrm{wt} \%$ fibres, the increase were only by $5 \%$ and $3 \%$ respectively. Although $8 \mathrm{~h}$ treated fibres exhibited maximum strength properties, but the composites prepared with them showed lower strength values. Maximum composite strength was obtained from the $4 \mathrm{~h}$ treated fibres. The fibres became rigid and somewhat brittle afterwards owing to the development of crystallinity causing high strength and low extensibility. On application of stress, these fibres suffered breakage due to increased brittleness

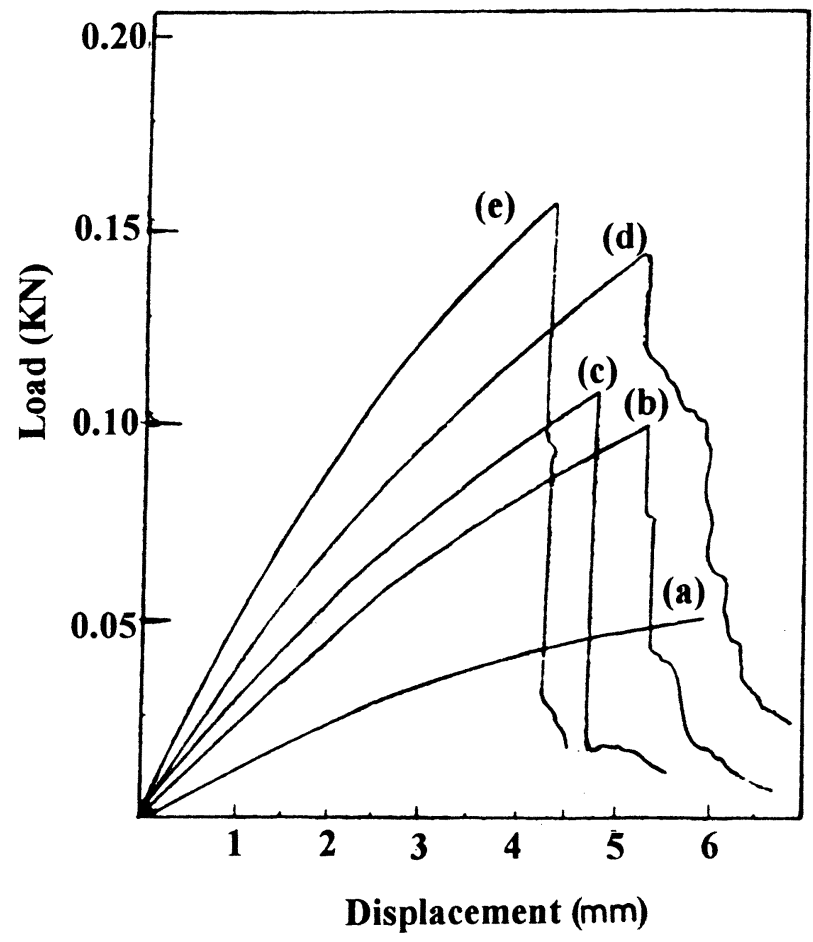

Figure 3. Load-displacement curves of jute reinforced composites: (a) vinylester resin; $23 \mathrm{wt} \%$ fibres, (b) untreated, (c) $4 \mathrm{~h} \mathrm{NaOH}$ treated; $35 \mathrm{wt} \%$ fibres, (d) untreated and (e) $4 \mathrm{~h}$ $\mathrm{NaOH}$ treated. and could not take part in effective stress transfer at the interface, thus lowering the strength of the composites.

The rates of improvements $(R)$ in the flexural strengths and modulus of the composites with wt $\%$ of $\mathrm{NaOH}$ treated fibre reinforcements from $2 \mathrm{~h}$ to $8 \mathrm{~h}$ have been shown in figures 4 and 5 .

The improvement occurred linearly with the increased wt\% fibre content. The slope of the composite properties with $0-4 \mathrm{~h}$ treated fibres was maximum and became shallower with $4-8 \mathrm{~h}$ treated fibres. This can be expressed by the following relation

$$
R=m \cdot W_{\mathrm{f}}+C
$$

where $R$ is the rate of change of the composite properties, $m$ the slope and $W_{\mathrm{f}}$ the weight of the fibre reinforcements. Taking the different slopes of ' $m$ ' from figures 4 and 5 , a plot of ' $m$ ' against alkali treatment time was depicted in figure 6.

A deflection at $4 \mathrm{~h}$ treatment was apparent imperative of the occurrence of two different failure modes before and after $4 \mathrm{~h}$ of $\mathrm{NaOH}$ treatment. Taking the strength values of fibres from Bledzki and Gassan (1999) the com-

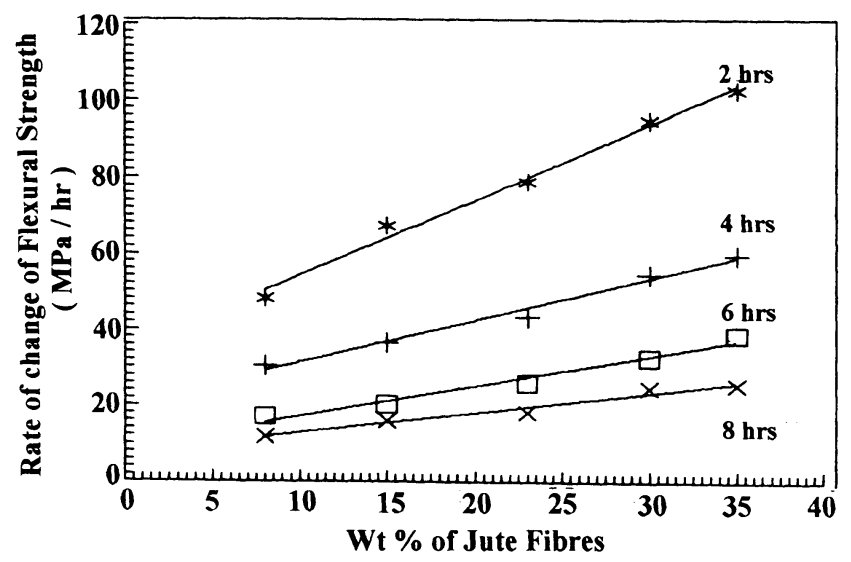

Figure 4. Variation of the rate of change of flexural strength of composites with varying wt $\%$ of alkali treated jute fibres.

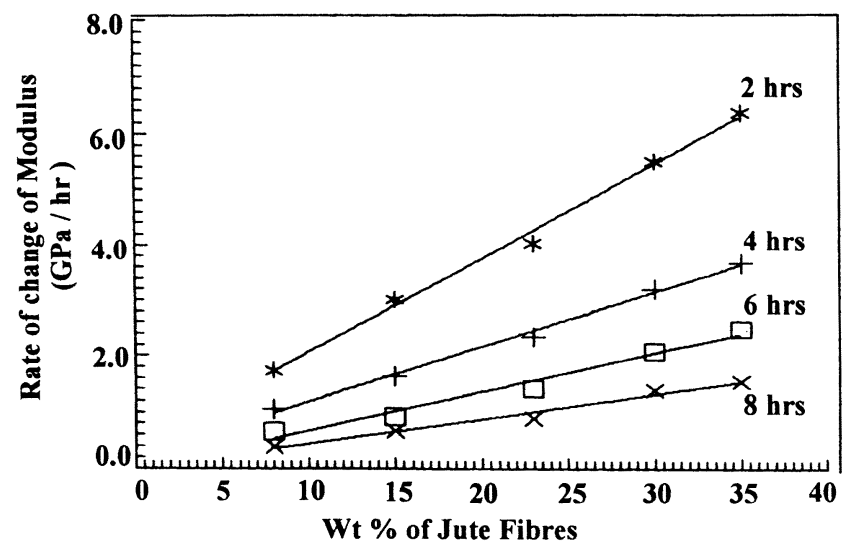

Figure 5. Variation of the rate of change of modulus of composites with varying wt $\%$ of alkali treated jute fibres. 
posite strengths were estimated applying the rule of mixtures. This was compared with the experimentally obtained flexural strengths of the composites prepared with $4 \mathrm{~h}$ treated and untreated fibres. The variation of the property with wt\% jute fibre reinforcement is shown in figure 7. A large difference between the estimated and actually measured values was observed. The improvements with alkali treated fibres for $4 \mathrm{~h}$ was apparent. The improvements in the experimental values were not linear, having the improvements more towards higher fibre loading. At $23 \mathrm{wt} \%$ fibre loadings, the composite flexural strengths were lower by $24 \%$ and $36 \%$ and for $35 \mathrm{wt} \%$ fibre loadings, they were lower by $16 \%$ and $29 \%$ from the estimated values for treated and untreated fibre compo-

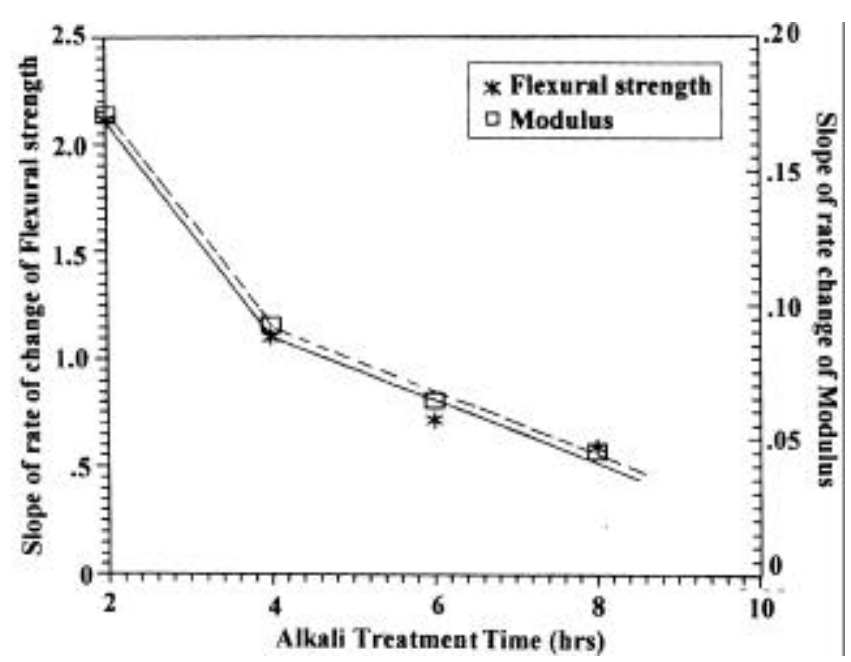

Figure 6. Effect of the alkali treatment time on the rate of change of flexural strength and modulus of the composites.

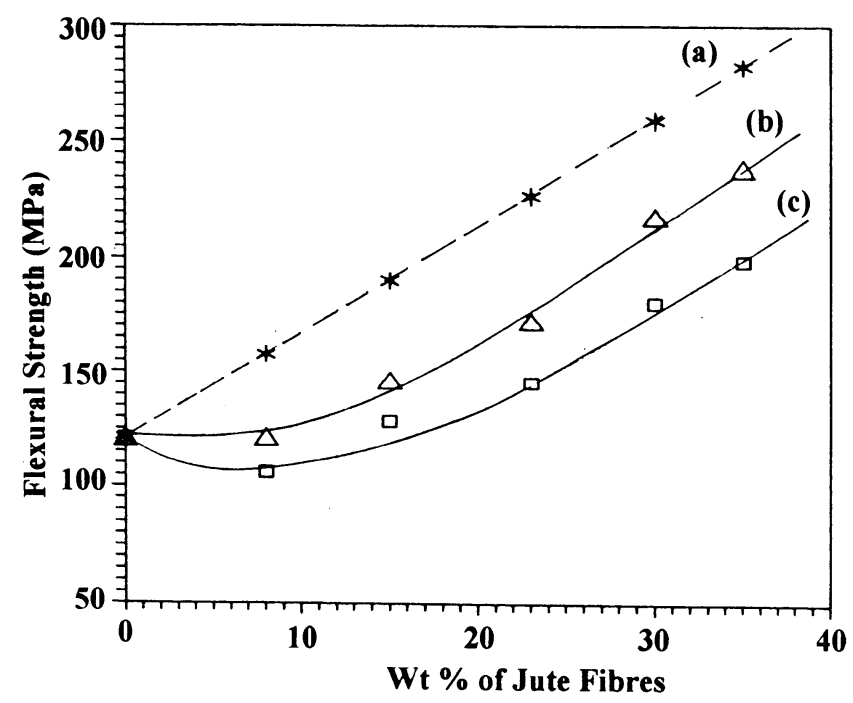

Figure 7. Variation of composite flexural strength with varying wt $\%$ of jute fibres: (a) theoretical, (b) experimental $(4 \mathrm{~h}$ alkali treated fibres) and (c) experimental (untreated fibres). sites respectively. Similar observations were made for the change in modulus also (figure 8).

The composite modulus were lower than the estimated modulus by $37 \%$ and $51 \%$ for $35 \mathrm{wt} \%$ composites and by $31 \%$ and $44 \%$ for $23 \mathrm{wt} \%$ composites for the treated and untreated fibres respectively. The modulus value of the fibres for the estimation of modulus from the rule of mixtures was taken from Roe and Ansell (1985). The theoretical estimation of strength and modulus from the rule of mixtures considers defect free fibres and composites. The observed percentage differences of the composite properties between the estimated and measured values, would actually be the total amount of \% defects in the composites incorporated during processing. Taking the relation

$$
\sigma_{\mathrm{c}}=V_{\mathrm{f}}\left(n_{1} e^{-k d_{1}}-n_{2} e^{-k d_{2}}\right)+n_{2} e^{-k d_{2}},
$$

modelled by Sarkar (1998) for the estimation of composite strength by modified rule of mixtures incorporating defects, where $\sigma_{\mathrm{c}}$ is the composite strength, $n_{1}$ and $n_{2}$ are fibre and matrix strengths at defect concentrations of $d_{1}$ and $d_{2}$, respectively, $k$ is a constant approximating 1 and $V_{\mathrm{f}}$ the vol\% of fibres, $d_{1}$ and $d_{2}$ were estimated. It was found that the total amount of defects in a $35 \mathrm{wt} \%$ composite was $30 \%$ against $29 \%$ found experimentally for composites prepared with the untreated fibres and $18.5 \%$ against $16 \%$ found experimentally for the composites having $4 \mathrm{~h}$ alkali treated fibres. The $d_{1}$ for untreated and $4 \mathrm{~h}$ treated fibres were $20 \%$ and $8.5 \%$ respectively, whereas $d_{2}$ was $10 \%$. The defects in the composites with untreated fibres relates to the poor wetting characteristics with an improvement on alkali treatment.

The improved properties of the fibres with alkali treatment for a longer duration was the result of dissolution of hemicellulose and development of crystallinity and fibrillation thus created superior bonding with vinylester resin

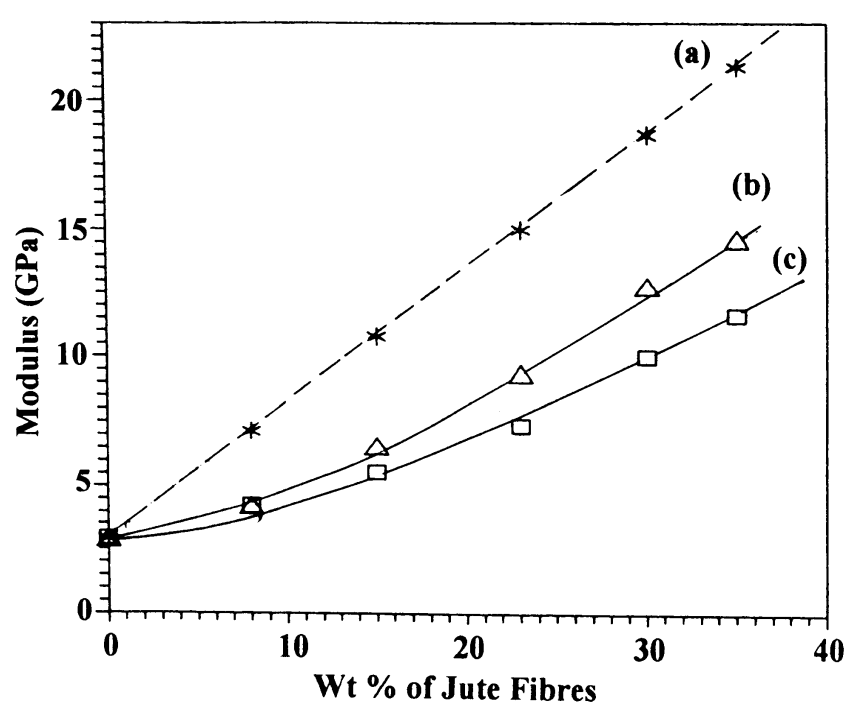

Figure 8. Variation of composite modulus with varying wt $\%$ of jute fibres: (a) theoretical, (b) experimental (4 h alkali treated fibres) and (c) experimental (untreated fibres). 


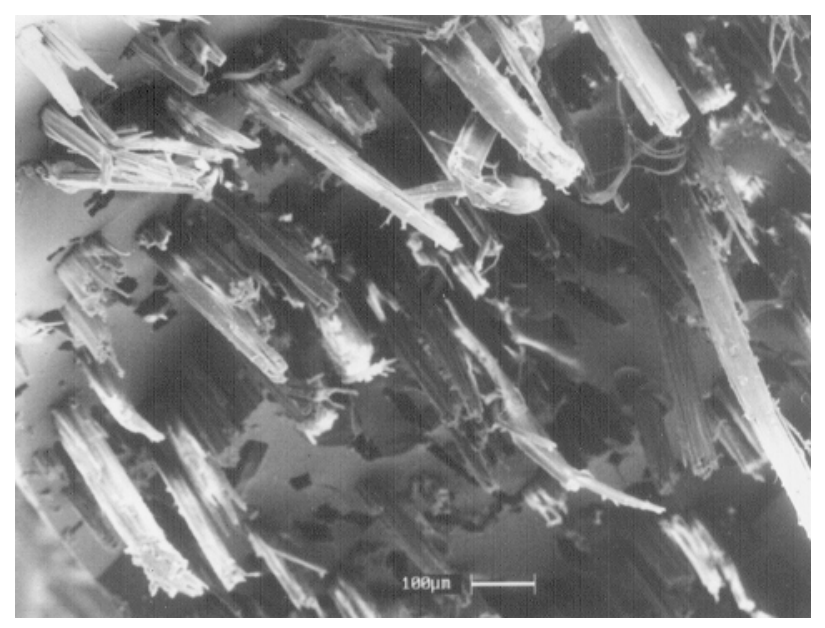

Figure 9. Fibre pull out and breakage in composites reinforced with $23 \mathrm{wt} \%$ untreated jute fibres.

matrix and resulted into superior properties of the composites. This was reflected in the fractured surfaces of the composites also when examined under SEM. The composites prepared with the $\mathrm{NaOH}$ treated jute fibres for shorter durations $(2-4 \mathrm{~h})$ had inferior bonding with the resin. The fibre breakage and pull out had been predominant (see figure 9), as demonstrated in load/displacement curve also. The matrix cracking and debonding of fibres at these stages were also prevalent (figure 10). The composites prepared with the alkali treated jute fibres for a longer duration $(6-8 \mathrm{~h})$ had a predominant transverse fracture with the minimum pull out (figure 11) of fibres, imperative of an increased load transfer characteristics from matrix to fibres as also revealed from the loaddisplacement curves (figure 3). Consequently, the deflection in the slope ' $m$ ' indicated two different modes of fracture between the composites prepared with alkali treated jute fibre for the shorter and longer durations.

In contrast, composites prepared with untreated fibres for all sets of $\mathrm{wt} \%$ of fibre reinforcement showed matrix failure followed by the fibre fracture and pull out irrespective of increased fibre loading due to the poor wetting characteristics by the vinylester resin.

\section{Conclusion}

The composites reinforced with alkali treated fibres showed improved mechanical properties. The improvement was maximum for the composites prepared with $4 \mathrm{~h}$ treated fibres at $35 \%$ fibre loading. The flexural strength improved by $20 \%$ and modulus by $23 \%$. The strength and modulus of the composites were found to be lower than the values estimated from the general rule of mixtures. For the composites with a 35\% fibre content, the strength was lower by $29 \%$ and $16 \%$ for the untreated and $4 \mathrm{~h}$ treated fibres and the modulus was lower by $51 \%$ and $37 \%$ for the untreated and $4 \mathrm{~h}$ treated fibres respectively. This reduction in strength was due to the incorporation of

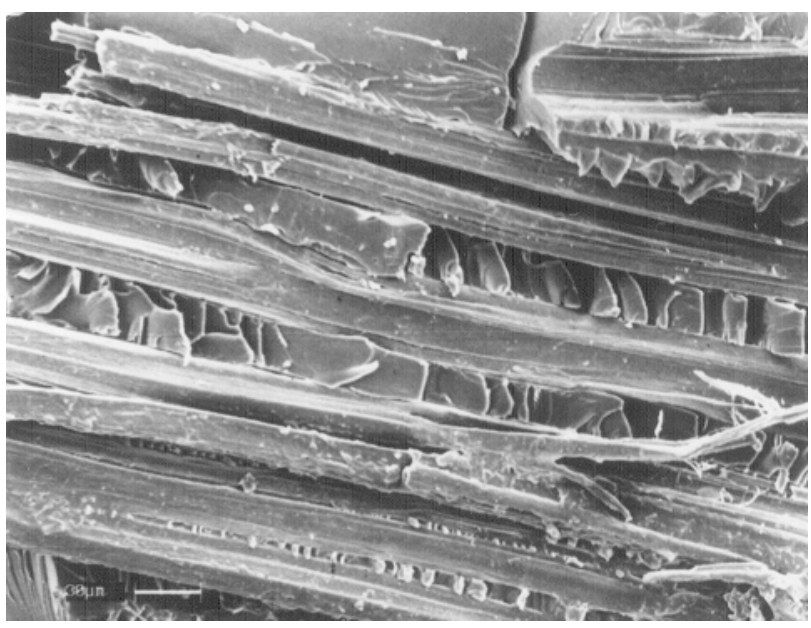

Figure 10. Matrix cracking and debonding of composites reinforced with $23 \mathrm{wt} \% 2 \mathrm{~h}$ alkali treated jute fibres.

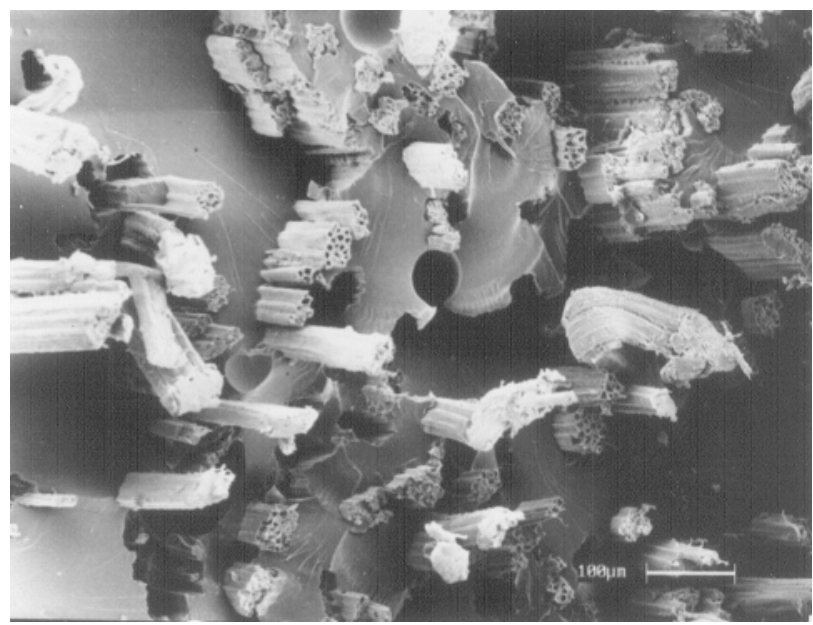

Figure 11. Transverse fracture of composites reinforced with $23 \mathrm{wt} \% 8 \mathrm{~h}$ alkali treated jute fibres.

defects in the composites during processing. From the modified rule of mixture, the defects were estimated to be $10 \%$ in the matrix, $20 \%$ and $8.5 \%$ in the untreated and $4 \mathrm{~h}$ treated fibres respectively.

The rate of change of flexural strength and modulus were found to be linear with wt $\%$ of alkali treated fibres and the slope being maximum for $2 \mathrm{~h}$ and minimum for $8 \mathrm{~h}$. The variation of slopes of the rate of change of flexural strength and modulus with alkali treatment time showed two separate zones with a deflection at $4 \mathrm{~h}$ treatment, indicating the possibility of two different failure modes before and after $4 \mathrm{~h}$ treatment. Fibre pull out was predominant up to $4 \mathrm{~h}$ and thereafter the transverse fracture occurred with minimum fibre pull out due to the superior bonding and improved tenacity and low extensibility of the fibres. A treatment time of $4 \mathrm{~h}$ was therefore optimal to get maximum strength of the vinylester composites reinforced with jute fibres treated with $5 \% \mathrm{NaOH}$ solution at $30^{\circ} \mathrm{C}$. 


\section{Acknowledgements}

Authors are indebted to the Council of Scientific and Industrial Research, New Delhi, for providing financial assistance during the course of the investigation. Sincere thanks are due to $\mathrm{Mr} \mathrm{K}$ Banerjee and $\mathrm{Mr} \mathrm{S} \mathrm{K} \mathrm{Dalui,}$ Central Glass and Ceramic Research Institute, Kolkata, for their help in the laboratory work. Mrs M Sarkar, IJIRA, Kolkata, is gratefully acknowledged for her unstinted support. We thank the Directors, Indian Association for the Cultivation of Science (IACS), Indian Jute Industries' Research Association (IJIRA) and Central Glass and Ceramic Research Institute (CG\&CRI), Kolkata, for facilities.

\section{References}

Bisanda E T N and Ansell M P 1991 Comp. Sci. \& Tech. 41165 Bledzki A K and Gassan J 1999 Proc. Polym. Sci. 24221

Chattopadhyay H and Sarkar P B 1946 Proc. Nat. Inst. Sci. India 1223
Gassan J and Bledzki A K 1999a Comp. Sci. \& Tech. 59 1303

Gassan J and Bledzki A K 1999b J. Appl. Polym. Sci. 71623

Milweski J V and Katz H S 1987 Handbook for reinforcements for plastics (New York: Van Nostrand Reinhold)

Mukherjee A, Ganguli P K and Sur D 1993 J. Tex. Inst. 84 348

Ott E, Spurlin H M and Grafflin M W (eds) 1954 Cellulose and cellulose derivatives, Part II (New York: Interscience) p. 863

Pothan L A, Thomas S and Neelakantan N R 1997 J. Reinforced Plastics 16744

Prasad S V, Pavithran C and Rohatgi P K 1983 J. Mater. Sci. 181443

Roe P J and Ansell M P 1985 J. Mater. Sci. 204015

Rout J, Mishra M, Nayak S K, Tripathy S S and Mohanty A K 1999 Polymers '99: Polymers Beyond AD 2000 (ed.) A K Ghosh p. 489

Samal R K, Mohanty M and Panda B B 1995 J. Polym. Mater. 12235

Sarkar B K 1998 Bull. Mater. Sci. 21329

Sarkar P B 1935 Indian J. Chem. Soc. 1223

Shah A N and Lakkad S C 1981 Fibre Sci. \& Tech. 1541 